\title{
Apparatus as milestones in the history of comparative psychology
}

\author{
DAVID A. WASHBURN, DUANE M. RUMBAUGH, and R. THOMPSON PUTNEY \\ Georgia State University, Atlanta, Georgia
}

\begin{abstract}
Significant apparatus developments from the history of comparative psychology are reviewed, including the contemporary trend toward computer use in research with nonhuman animals. It is argued that milestone apparatus served not only to open new lines of inquiry but also to shape or delimit the nature of the answers that were obtained.
\end{abstract}

There are several themes around which the history of psychology, or any science, can be organized, including delineation of the zeitgeists, dominant paradigms, and the significant individuals of each particular era. Within comparative psychology, Beach (1950) popularized the strategy of examining chronologically the content of published papers according to the species studied. Updated on each significant anniversary, his and similar reviews represent a means of assessing both the current and the historical status of the field that is unique to comparative psychology.

The present historical review follows a different strategy, focusing on the dominant or influential apparatus of a historical period rather than on species. Like identifying the significant individuals in the history of a discipline, such a review is necessarily selective. On the other hand, the journal literature, introductory textbooks, and several review chapters (e.g., Bitterman, 1966; Fobes \& King, 1982) provide consensus on several "milestone" apparatus. A journal-by-journal review has been eschewed for the present purposes for two principal reasons. First, the frequency with which a particular type of apparatus is employed tends to be highly correlated with the species of choice, and journal-by-journal analyses of species are available (e.g., Beach, 1950; see also Dewsbury, 1984). Second, because apparatus are subject to numerous modifications, shunning a strict frequency count at this point avoids the inevitable need to make arbitrary decisions regarding what variations constitute a new apparatus versus an adaptation of the same type. Rather, the present review highlights those research tools that have throughout history contributed to, and been shaped by, prevalent theoretical positions and stimulated new areas of inquiry. Frequently, it will be argued, these apparatus have also constrained, delimited, or modulated the answers to those empirical questions.

This research was supported in part by Grant NAG2-438 from the National Aeronautics and Space Administration to Georgia State University. Additional support was provided by Grant HD-06016 from the National Institutes of Health and by the Coilege of Arts and Sciences of Georgia State University. Correspondence should be sent to David A. Washburn, Sonny Carter Life Sciences Laboratory, Department of Psychology, Georgia State University, Atlanta, GA 30303, or via Bitnet to psydaw@gsuvm1.

\section{Problem Boxes and Mazes}

Although the roots of comparative psychology extend earlier, the present review begins at the turn of the century with Thorndike's (1898) puzzle boxes, principally for cats, and Small's $(1900,1901)$ studies of maze learning in rats. The rationale for considering these two major developments together extend beyond the temporal proximity of their construction. In many ways, the puzzle or problem box and the maze were seen and used as two manifestations of the same procedure; in point of fact, Thorndike (1898) used the maze as if it were just another problem box, albeit one in which the problem was spatial (i.e., learn to traverse the maze). Trial and error necessarily characterized learning in each, and each stressed the importance of response latency-the time required to exit the maze or the problem box-although error data were also available.

One feature that distinguishes the two apparatus is the "naturalness" of the procedures (or what today would be termed the "ecological validity" of each). Mazes were developed because they permitted experimental analysis of behavior that was extant in nature. That is, species do locomote from place to place, within environments that for an animal are maze-like, typically without losing their way. Small (1901) and his colleagues expressed great concern that his experimental situation be as natural as possible, predominant use of the Hampton Court maze pattern notwithstanding. On the other hand, organisms are infrequently confronted with the type of challenge a problem box presents, at least in nondomesticated environs. This criticism was levied as strongly by Thorndike (1898) himself as by his staunchest rivals (Mills, 1899). Notwithstanding, each apparatus opened the door (so to speak) for the laboratory investigation of animal behavior. Both (particularly the maze) enjoy contemporary use for a variety of subject areas in comparative psychology.

\section{Sticks and Stones}

It was Köhler (1925) who, using methods previously employed by Hobhouse (1901), provided early opposition to the Thorndikian paradigm for comparative psychology. Köhler's approach was remarkably atechnological. Common items such as sticks, rope, stones, and boxes formed 
the apparatus base for a new paradigm of comparative investigation. The familiar experiments in which apes were required to stack boxes or use sticks in order to obtain food served to provide experimental control for the types of "intelligent" behaviors otherwise recorded only in anecdotes, and certainly absent from problem-box and maze solving. Notwithstanding, the importance of Köhler's methods lies not in their substantial procedural innovativeness but rather in the underlying assumptions about animals (specifically, primates) that inspired the procedures. Köhler noted that the problem box and the maze afforded an organism no opportunity to produce an intelligent response. Problem-box solutions were concealed and only arbitrarily related to the desired outcome, and mazes were by design random in solution. Consequently, each apparatus predisposed trial and error to be the most effective response strategy. Not surprisingly then, psychologists observed that the animals learned by trial and error.

In contrast, Köhler (1925) selected experimental methods that permitted learning on other than a trial-and-error basis. Both response accuracy (particularly on novel trials) and the topography of responding were important data, rather than latencies or learning rates. By providing all the salient components of task solution to the animal's perceptual field, Köhler found that subjects were capable of achieving rapid, "insightful"' solutions to the problems. Of course, the apes could have solved any of the problems using trial and error; that they did not, Köhler argued, was indicative of substantial complexity and efficiency in ape intelligence.

Köhler's "apparatus" remains popular. Variations on this paradigm have incorporated the general features both of mazes (Köhler, 1925; Menzel, 1978; Tolman, 1932) and of problem boxes (e.g., Visalberghi, 1990). Tolman's elevated maze, in which the rat traversed runways that had no sidewalls, showed that rats can manifest a form of insight when given the opportunity, but they return to trial-and-error learning when sidewalls make visual inspection of the entire problem impossible. Tool-use, problemsolving, and similar research efforts frequently combine the methods of Köhler with problem-box-like devices to determine whether animals can, for example, use a stick to remove a peanut from a tube (Visalberghi, 1990) or make a stone knife to open a baited box (Toth, Schick, Savage-Rumbaugh, Sevcik, \& Rumbaugh, 1993).

\section{Multiple Choice and the WGTA}

Although his methods remain popular, Köhler's (1925) interpretations were attacked from several fronts. Schiller (1952) and others criticized those conclusions based on research using procedures similar to Köhler's. Additionally, Harlow (1949) attempted to demonstrate that "insight" was a manifestation of a subject's learning history (resulting in learning set or "learning to learn"). For his research, Harlow developed a choice apparatus based loosely on the familiar T-maze. Yerkes (1907) had modified the standard maze apparatus by providing a visible discriminative stimulus in each arm of a bifurcation, thereby permitting the subject nonspatial cues for responding (see also the "formboard" and similar innovations developed by Kluver, 1933). With this apparatus, Yerkes was able to study (and, in retrospect, underestimate) the capacity of mice to learn to respond differentially to different stimuli. A further modification was described by Lashley (1930) and became known as the Lashley jumping stand. Lashley retained the discriminative choice aspects of the Yerkes device while eliminating the runways carried over from maze work. Rather, the subjects (rats) were made to leap from a platform to one of two cards, each of which occluded access to a feeding platform. One card would give way, providing the animal with a safe landing and reinforcement; the other card bounced the subject to a net below. With this apparatus, Lashley demonstrated that rats are quite good discriminative learners.

Harlow (1949) adapted this choice procedure for primates, and the Wisconsin General Test Apparatus (WGTA) became a standard testing apparatus for nonhuman primates for the next four decades. In the WGTA, plaques and cards (à la Yerkes and Lashley) were typically replaced by junk objects as discriminative stimuli (owing in part to the relative advantage of learning stereometric vs. planimetric stimuli), with the reward hidden beneath one of the discriminanda. Reaching or touching typically replaced running or jumping as response modes. Like its antecedents, however, the WGTA afforded a researcher clear accuracy data. Harlow pioneered the use of this apparatus in the classic experiments on the development of learning set; similar work has since been conducted with a variety of species, with little substantive procedural alteration.

\section{Simple Operant}

While Yerkes, Lashley, and Harlow were producing a multiple-choice apparatus from the maze procedure, the behaviorist perspective was leading to a modification of the old problem-box notion. Skinner (1932) introduced what he termed a "repeating problem box," more commonly known as the operant chamber or the "Skinner box." The operant chamber has in fact been described as a problem box that delivers food rather than releasing the subject (Bitterman, 1966). However, it differs in that the quality of responding and the latency of responding, characteristic of Thorndike's (1898) research, are replaced by a single dominant measure: the rate of responding.

Like the WGTA, the operant chamber was designed to make obvious the discriminative cues for responding; in fact, the operant chamber was stripped of everything except stimuli and responses. The notion of "choice" became unnecessary as the behaviorist view of animals (including humans) as response generators became more popular. The tendency with each modification of the apparatus was toward simplicity, and as a consequence, the operant chamber was quite unlike anything an organism would face in nature. On the other hand, the behaviors and contingencies studied using this device were so basic as to suggest widespread generality even in the absence of face validity. Additionally, the apparatus could be em- 
ployed with a variety of species, including the relatively inexpensive and available rat and pigeon, whereas the WGTA was designed primarily for use with primates. Consequently, the operant chamber became an enormously popular apparatus for comparative psychology, and the behavioral principles derived from manipulation of stimulus-response-reward contingencies were purported to account for most or all of behavior.

\section{Computer Use by Nonhuman Animals}

With the rise of cognitive psychology in the last 30 years, accompanied by the advent of both the computer metaphor in psychology and the availability of computer resources for science in general, a new set of apparatus is being developed. These attempts are primarily spawned by (1) the desire to automate previous apparatus such as the WGTA or operant chamber, and (2) the desire to investigate new processes not accessible with the traditional apparatus of the field. Perhaps for the first time in history, apparatus developed initially for research with humans has found significant applications into areas of comparative inquiry.

An examination of the literature reflects the gradual infusion of computer technology into comparative psychology, as well as how far the field still lags behind human cognitive psychology. In the 1970s, journals such as Animal Learning \& Behavior, Journal of Comparative Psychology, Journal of the Experimental Analysis of Behavior, and Journal of Experimental Psychology: Animal Behavior Processes reported very little computer use. Over $60 \%$ of the articles published in these journals were based on operant devices, with variations on maze and runway apparatus accounting for $21 \%$ of the other publications. Most research with nonhuman primates used WGTA or similar multiple-choice devices, although this accounts for only about $5 \%$ of the articles surveyed. When used, computers controlled experimental procedures and maintained recorded data.

The recent literature reflects similar apparatus patterns, suggesting one reason why major reviews of developments in apparatus are so infrequent. Notwithstanding, change is apparent even in the first few years of the 1990s. Although operant apparatus remain predominant in the literature, computers are gaining increased use. Most investigators reported using computers to maintain data and control experimental manipulations, and their use for stimulus presentation and response detection is common. Interestingly, computers are frequently used for simulation of animal behavior, particularly in conjunction with operant data.

Of special note within this recent literature is the emergence of computer use by nonhuman animals in research, in contrast to computer use in research with nonhuman animals. That is, computers are being used as an apparatus per se rather than just a tool to support other apparatus, so that nonhuman animals, like humans, are being tested directly with computers. One such technological advance is the Language Research Center's Computerized Test System (LRC-CTS) developed at Georgia State University for use with primates (Rumbaugh, Richardson, Washburn, Savage-Rumbaugh, \& Hopkins, 1989). This apparatus, currently in use at over two dozen research laboratories, permits computer generation and presentation of stimuli to which subjects respond by manipulating a joystick. As such, it presents a radical change both in procedure and in perspective from the operant chamber. Whereas response rate remains an available datum, it is largely supplanted by the qualitative (accuracy and response topography) and quantitative (response time) measurements of cognitive psychology. The stark simplicity of the free operant is replaced with a richness of both stimulus and response options. Consequently, the range of constructs studied using the LRC-CTS and similar devices include learning, memory, attention, perception, metacognition, tracking, motivation, prediction, laterality, numerical competence, and psychological well being (e.g., Andrews, 1993; Hopkins, Morris, \& Savage-Rumbaugh, 1991; Washburn, 1993).

Other devices for computer use by nonhuman animals have been reported. Significant advances in the ape language field have recently been reported on the basis of research with chimpanzees that use computerized keyboards (Savage-Rumbaugh et al., 1993). Visual search has been studied by requiring pigeons or apes to respond to computer-generated stimuli by pecking or touching the screen (Blough, 1993; Tomonaga, 1993). Computerized methods for assessing tracking by pigeons (Neiworth \& Rilling, 1987) and activity patterns by rats (Silverman, Chang, \& Russell, 1988) have been described. Mental rotation data have been reported for baboons that manipulate a joystick in accordance with task demands (Vauclair, Fagot, \& Hopkins, 1993). Serial learning by monkeys has also been studied using touch-screen technology (e.g., Swartz, Chen, \& Terrace, 1991).

\section{Discussion}

A "developmental tree" of apparatus in comparative psychology is shown in Figure 1. Description of the history (or indeed the present state) of comparative psychology as revealed by apparatus development may inspire the suggestion that comparative psychology (vs. ethology, for example) is " about" instrumentation and laboratory research. Dewsbury (1984) summarized this reproach, and even Köhler cautioned "against studying apparatus rather than the animal" (Schneirla, 1946, p. 312). Menzel (1967), noting the preponderance of apparatus named for their designers, proposed several "new" apparatus, including the "Menzel jumping stand" (a tree) and the “Delta Primate Center General Test Apparatus"' (the jungle)! Although the criticism that a discipline is too instrument driven can probably be made about many sciences, there are particular dangers to this "myth," as it was called by Dewsbury (1984), for comparative psychology. Dewsbury countered that comparative psychology is "about" observation and description as much as control and prediction, and that such observation has only infrequently been dependent on technology. The present review does not contradict this defense. 

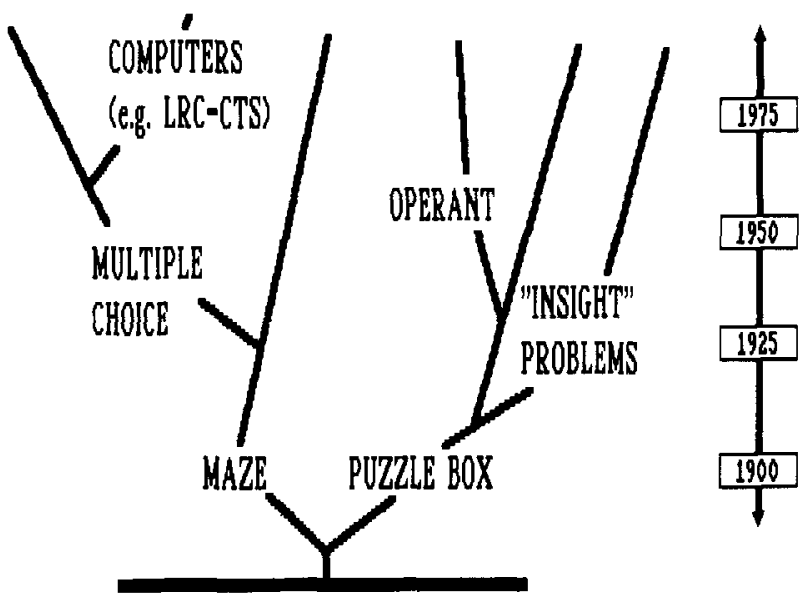

Figure 1. General trends in the development of apparatus in comparative psychology.

Also, the present review is not designed to contrast the relative strengths and weaknesses of various research tools or to address the veracity, for example, of Köhler's claims vis-à-vis Thorndike and the associationists. Each apparatus has been proven - and continues to be-important for comparative psychology. Each of the varied findings derived from application of these tools (e.g., trial-and-error learning, insight, operant conditioning, cognitive processes) is necessary, and none is sufficient, to characterize animal behavior (see Appendix).

Rather, it is illustrative to note that, throughout the history of comparative psychology, the apparatus of choice and the prevailing theoretical viewpoint enjoyed a reliable, circular relationship. What each investigator found was shaped or delimited by what was being looked for, as well as by the apparatus each used to look. Thorndike and Small presumed that animals learned by trial and error because animals could learn no other way in their research. Köhler's predisposition to believe that animals were capable of insightful learning was no less influential in his choice of methods, which in turn influenced his findings. Similarly, organisms tend to respond in accordance with simple operant principles when their entire world, and repertoire of adaptive responses, consists of simple responses to overt contingencies. In contrast, the uniqueness of the LRC-CTS and similar computerbased technologies resides in the rich cognitive perspective that fuels their development. The animal is seen not as an intermediate step in an inevitable stimulus-response chain, nor even as a simple associative mechanism forming and breaking response habits. Rather, the subjects are viewed as intelligent organisms actively seeking to learn, to organize, to control, and to make choices. Still, the future may reveal that the assumptions that promote the design and use of computerized testing systems, as well as the systems themselves, mold and constrain the nature of the present findings as well.

Historical examples of this can certainly be cited. As was noted earlier, Yerkes (1907) underestimated the discriminative capacity of the mouse in light of subsequent work, such as with the Lashley jumping stand. One hypothesis proffered to account for these differences rests on the observation that the jumping stand and the subsequent WGTA, but not Yerkes apparatus, afford direct response contact with the discriminanda (i.e., the subjects jump into cards or touch discriminanda in the former but not the latter apparatus). Abundant subsequent literature (e.g., Stollnitz, 1965) attests to the influence of stimulusresponse spatial discontiguity on learning: To the degree that response loci are removed in space from salient stimuli, performance is compromised or learning is denied. However, research with the LRC-CTS revealed that learning can be comparable or even elevated in a spatially discontiguous situation with levels obtained with the WGTA (Washburn, Hopkins, \& Rumbaugh, 1989). Far from being paralyzed by substantial distance between stimulus and response loci, rhesus monkeys flourished in a discrimination learning task. It now seems clear that the stimulusresponse spatial discontiguity issue, held as psychological law in the animal learning literature for 40 years, is itself an artifact of the WGTA and similar testing apparatus.

Other examples exist; many competencies once thought unique to humans (e.g., language, target prediction) have been identified in computer-using animals. The conclusion is clear. Apparatus developments have served both to empower and to delimit the comparative psychologist in the quest to understand animal behavior. They have both reflected the assumptions and predispositions of the dominant paradigm of a field and have helped to shape and alter the balance of power of these paradigms. The opportunities afforded by each technological breakthrough must be accompanied by an awareness of ways in which findings may be biased or obstructed by the limitations of the apparatus.

\section{REFERENCES}

ANDREws, M. W. (1993). Video-task paradigm extended to Saimiri. Perceptual \& Motor Skills, 76, 183-191.

BEACH, F. A. (1950). The snark was a boojum. American Psychologist, 5, 115-124.

BitTerman, M. E. (1966). Animal learning. In J. B. Sidowski (Ed.), Experimental methods and instrumentation in psychology (pp. 451484). New York: McGraw-Hill.

BLough, D. S. (1993). Features of forms in pigeon perception. In W. K. Honig \& J. G. Fetterman (Eds.), Cognitive aspects of stimulus control (pp. 263-277). Hillsdale, NJ: Erlbaum.

DewsBuRY, D. A. (1984). Comparative psychology in the Twentieth Century. Stroudsburg, PA: Hutchinson Ross.

FoBEs, J. L., \& KING, J. E. (1982). Measuring primate learning abilities. In J. L. King \& J. E. King (Eds.), Primate behavior (pp. 289326). New York: Academic Press.

HarLow, H. F. (1949). The formation of leaming sets. Psychological Review, 56, 51-65.

HobHouse, L. T. (1901). Mind in evolution. London: Macmillan.

Hopkins, W. D., Morris, R. D., \& Savage-Rumbaugh, E. S. (1991). Evidence for asymmetrical hemispheric priming using known and unknown warning stimuli in two language-trained chimpanzees ( $P$ an troglodytes). Joumal of Experimental Psychology: General, 120, 46-56.

KLUVER, H. (1933). Behavior mechanisms in monkeys. Chicago: University of Chicago Press.

KöHLER, W. (1925). The mentality of apes. New York: Harcourt, Brace.

LASHLEY, K. S. (1930). The mechanism of vision: I. A method for rapid analysis of pattern-vision in the rat. Journal of Genetic Psychology, 37, 453-460. 
MENZEL, E. W. (1967). Naturalistic and experimental research on primates. Human Development, 10, 170-186.

Menzel, E. W. (1978). Cognitive mapping in chimpanzees. In S. H. Hulse, H. Fowler, \& W. K. Honig (Eds.), Cognitive processes in animal behavior (pp. 375-422). Hillsdale, NJ: Erlbaum.

MiLls, W. (1899). The nature of animal intelligence and the methods of investigating it. Psychological Review, 6, 262-274.

Neiworth, J. J., \& Rilling, M. E. (1987). A method for studying imagery in animals. Journal of Experimental Psychology: Animal Behavior Processes, 13, 203-214.

Rumbaugh, D. M., Richardson, W. K., Washburn, D. A., SavageRumbaugh, E. S., \& HopKINS, W. D. (1989). Rhesus monkeys (Macaca mulatta), video tasks, and implications for stimulusresponse spatial contiguity. Journal of Comparative Psychology, 103, 32-38.

Savage-Rumbaugh, E. S., Murphy, J., Sevcik, R. A., Brakke, K. E., Williams, S. L., \& Rumbaugh, D. M. (1993). Language comprehension in ape and child. Monographs of the Society for Research in Child Development, 58 (3-4), v-221.

SCHILleR, P. H. (1952). Innate constituents of complex responses in primates. Psychological Review, 59, 177-191.

SCHNeIRLA, T. C. (1946). Contemporary American animal psychology in perspective. In P. L. Harriman (Ed.), Twentieth Century psychology (pp. 306-316). New York: Philosophical Library.

Silverman, R. W., Chang, A. S., \& Russell, R. W. (1988). Measurement of activity in small animals using a microcomputer-controlled system. Behavior Research Methods, Instruments, \& Computers, 20, 537-540.

SkINNER, B. F. (1932). On the rate of formation of a conditioned reflex. Journal of General Psychology, 7, 274-285.

SMaLL, W. S. (1900). An experimental study of the mental processes of the rat. American Joumal of Psychology, 11, 135-165.
SMALL, W. S. (1901). Experimental study of the mental processes of the rat II. American Journal of Psychology, 12, 206-239.

Stollnitz, F. (1965). Spatial variables, observing responses, and discrimination learning sets. Psychological Review, 72, 247-261.

Swartz, K. B., Chen, S., \& Terrace, H. S. (1991). Serial learning by rhesus monkeys: I. Acquisition and retention of multiple four-item lists. Joumal of Experimental Psychology: Animal Behavior Processes, 17, 396-410.

THORNDIKE, E. L. (1898). Animal intelligence: An experimental study of the associative processes in animals. Psychological Review Monograph Supplement, 2, 1-109.

Tolman, E. C. (1932). Purposive behavior in animals and men. New York: Century.

TomonAGA, M. (1993). Use of multiple-alternative matching-to-sample in the study of visual search in a chimpanzee (Pan troglodytes). Joumal of Comparative Psychology, 107, 75-83.

Toth, N., Schick, K. D., Savage-Rumbaugh, E. S., Sevcik, R. A., \& RumbaUGH, D. M. (1993). Pan the tool-maker: Investigations into the stone tool-making and tool-using capabilities of a bonobo ( $P$ an paniscus). Journal of Archaeological Science, 20, 81-91.

VAuClair, J., FAGOT, J., \& HopKINS, W. D. (1993). Rotation of mental images in baboons when the visual input is directed to the left cerebral hemisphere. Psychological Science, 4, 99-103.

Visalberghi, E. (1990). Tool use in Cebus. Folia Primatologica, 54, 146-154.

Washburn, D. A. (1993). The stimulus movement effect: Allocation of attention or artifact? Journal of Experimental Psychology: Animal Behavior Processes, 19, 1-10.

Washburn, D. A., Hopkins, W. D., \& Rumbaugh, D. M. (1989). Automation of learning-set testing: The video-task paradigm. Behavior Research Methods, Instruments, \& Computers, 21, 281-284.

Yerkes, R. M. (1907). The dancing mouse. New York: Macmillan.

APPENDIX

\begin{tabular}{|c|c|c|c|c|}
\hline Apparatus & Designer & Measure & Advantages & Disadvantages \\
\hline Puzzle box & Thorndike & Response latency & $\begin{array}{l}\text { Novel challenges } \\
\text { New learning } \\
\text { Experimental } \\
\text { control } \\
\text { Inexpensive }\end{array}$ & $\begin{array}{l}\text { Unlike nature } \\
\text { Only permits trial- } \\
\text { and-error learning }\end{array}$ \\
\hline Maze & Small & Response latency & $\begin{array}{l}\text { Novel challenges } \\
\text { New learning } \\
\text { Control } \\
\text { Inexpensive } \\
\text { Like nature }\end{array}$ & $\begin{array}{l}\text { Only permits trial- } \\
\text { and-error learning } \\
\text { Particularly suited } \\
\text { for rodents }\end{array}$ \\
\hline "Insight" devices & Köhler & Response pattern & Permits insight & $\begin{array}{l}\text { Relies on past } \\
\text { experience } \\
\text { Loss of control } \\
\text { Labor intensive }\end{array}$ \\
\hline Choice apparatus & $\begin{array}{l}\text { Yerkes } \\
\text { Lashley } \\
\text { Harlow }\end{array}$ & Accuracy & $\begin{array}{l}\text { Novel challenges } \\
\text { New learning } \\
\text { Control } \\
\text { Replicable }\end{array}$ & Labor intensive \\
\hline Operant apparatus & Skinner & Response rate & $\begin{array}{l}\text { Control } \\
\text { Simple behavior } \\
\text { Automated } \\
\text { Novel challenges } \\
\text { New learning } \\
\text { Replicable }\end{array}$ & $\begin{array}{l}\text { Limited in range } \\
\text { and type of } \\
\text { behavior }\end{array}$ \\
\hline $\begin{array}{l}\text { Computer-based } \\
\text { apparatus }\end{array}$ & $\begin{array}{l}\text { e.g., } \\
\text { Rumbaugh } \\
\text { Blough } \\
\text { (many } \\
\text { others) }\end{array}$ & $\begin{array}{l}\text { Latency } \\
\text { Response pattern } \\
\text { Accuracy } \\
\text { Response rate } \\
\text { Response time }\end{array}$ & $\begin{array}{l}\text { Variety } \\
\text { Novel challenges } \\
\text { New learning } \\
\text { Control } \\
\text { Automated } \\
\text { Replicable }\end{array}$ & Expensive \\
\hline
\end{tabular}

